\title{
South China Sea Wave Characteristics under Combined Wind Forcing of Typhoon and Winter Monsoon
}

\author{
Peng Q ${ }^{1,2 *}$ \\ ${ }^{1}$ Institute of Oceanology, Chinese Academy of Sciences, China \\ ${ }^{2}$ Key Laboratory of Ocean Circulation and Waves, Chinese Academy of Sciences, China
}

Received: 制April 28, 2018; Published: 制 May 07, 2018

*Corresponding author: Peng QI, Institute of Oceanology, Chinese Academy of Sciences, Key Laboratory of Ocean Circulation and Waves, Chinese Academy of Sciences, Qingdao 266071, China

Abbreviations: SCS: South China Sea; CCMP: Cross Calibrated Multi Platform

\section{Short Communication}

Since monsoon winds prevail in South China Sea (SCS), SCS is unique for investigating wave characteristics during a typhoon's passage in conjunction with steady monsoon wind forcing. This study investigated SCS wave characteristics using Wave Watch III, the third-generation wave model with winter typhoon forcing. The model was forced by a high resolution wind field from NASA's Cross Calibrated Multi Platform (CCMP) ocean surface winds combined with the tropical cyclone wind model. The Wave Watch III model was evaluated using Jason-2 altimetry observations during the period of Typhoon Durian (2006). The effects of typhoon and winter monsoon on the wave characteristics in SCS were analyzed with two situations:
a) Realistic winds
b) Ideal typhoon winds. The typhoon effect was simulated using ideal typhoon winds (Situation-2). The winter monsoon effect was simulated using the difference between Situation-1 and Situation-2 (Figures 1-5).
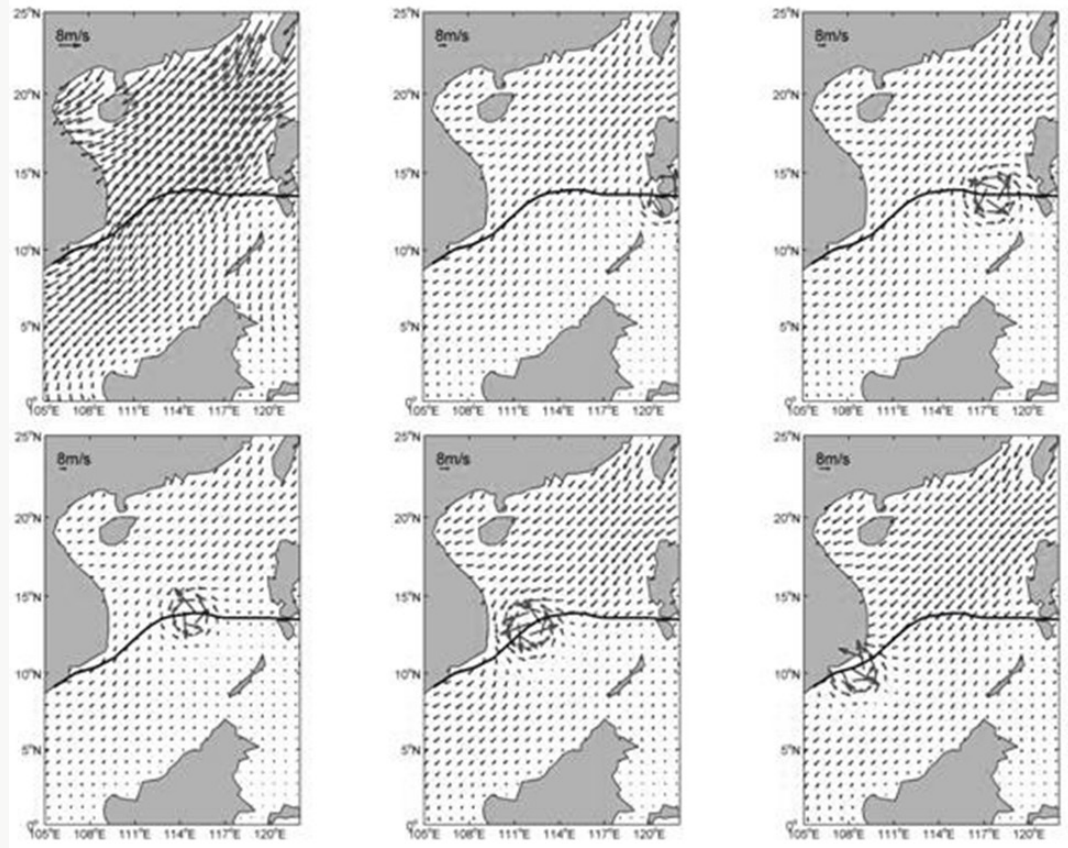

Figure 1: The global harvest of marine and fresh water aquatic plants from 1950 to 2009. 

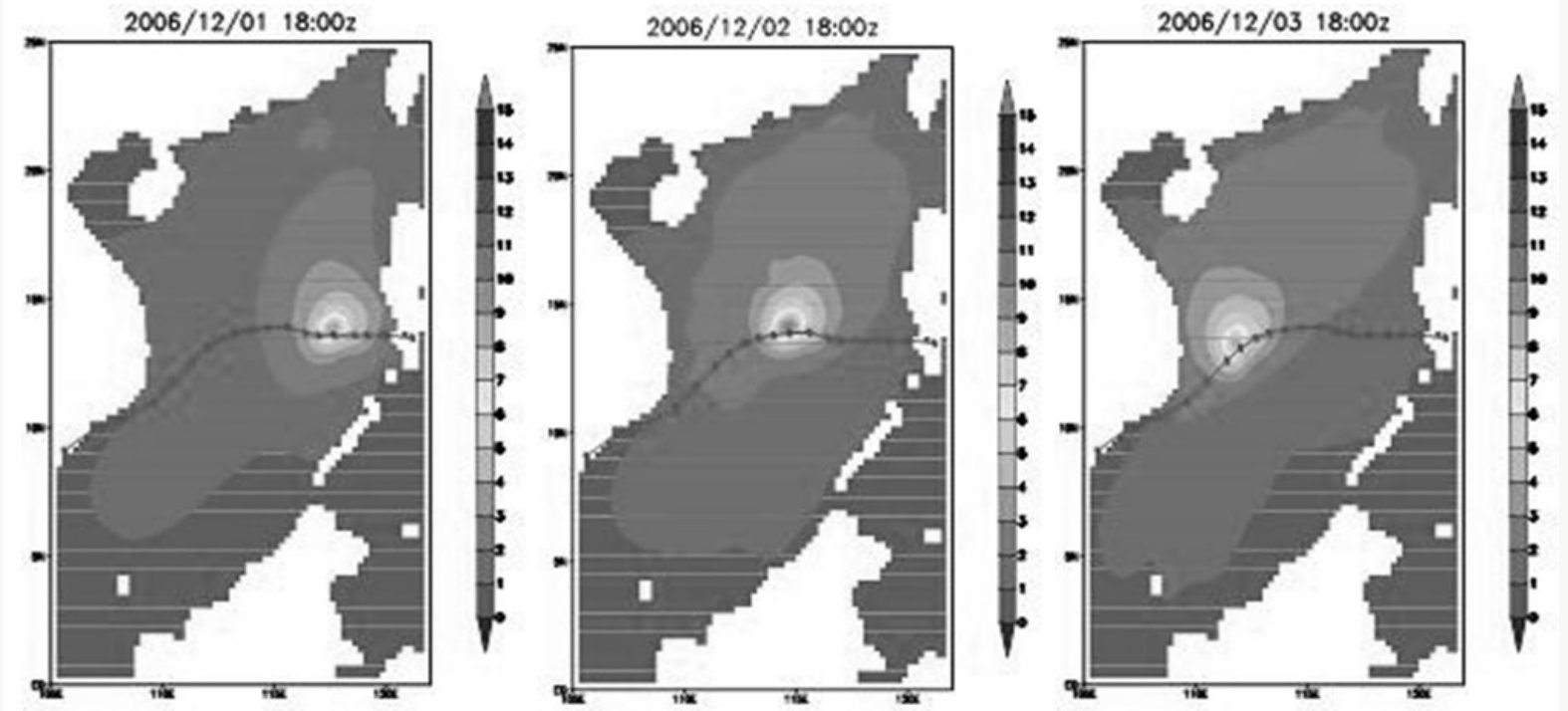

Figure 2: Daily evolution of Hs in SCS during the passage of Typhoon Durian (2006).
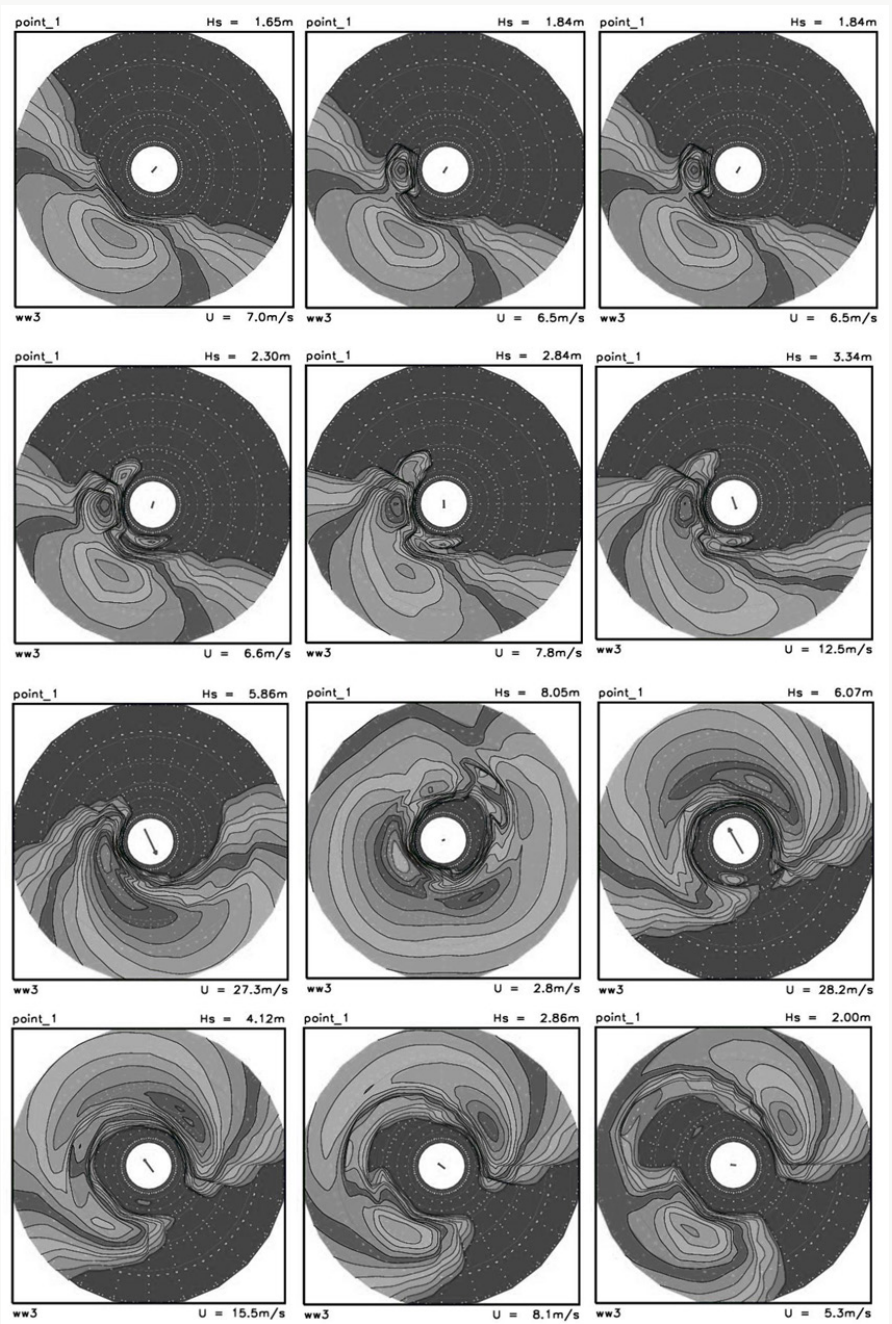

Figure 3: Six hour evolution of directional wave spectra on point_1 $\left(13.8^{\circ} \mathrm{N}, 114.0^{\circ} \mathrm{E}\right)$ from $0600 \mathrm{UTC}$ on December 1 to $1800 \mathrm{UTC}$ on December 4, 2006. Typhoon Durian was at this location at 0000UTC on December 3. Arrow presents the wind speed and direction. 

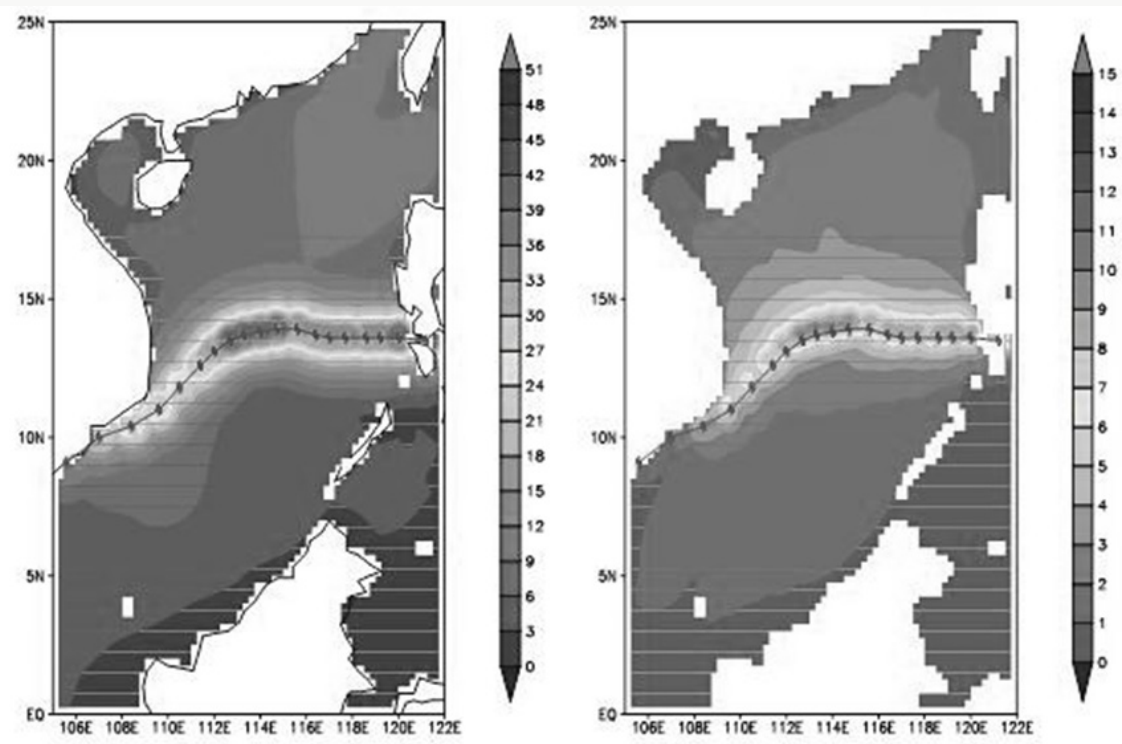

Figure 4: Horizontal distributions during passage of Typhoon Durian (2006): maximum forcing wind speeds (left), and maximum Hs calculated using Wave Watch III (right).
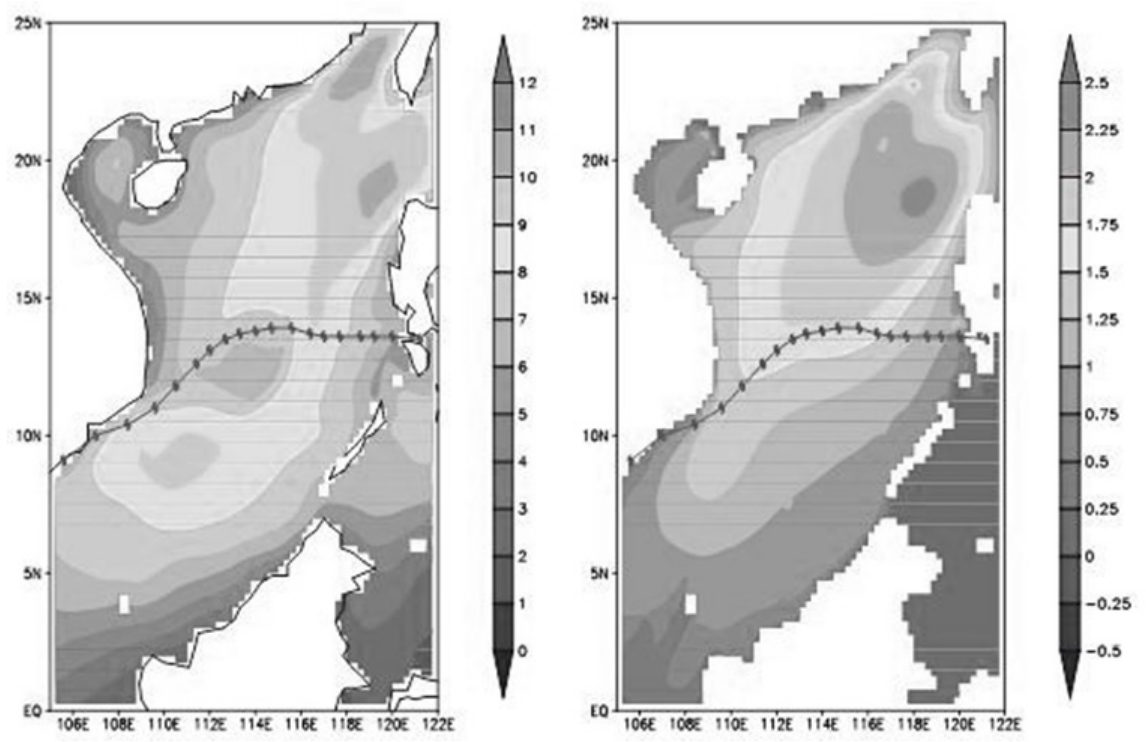

Figure 5: Differences between two situations (with monsoon winds minus without monsoon winds) in: maximum wind speed (left), and maximum Hs (right).

Along Typhoon Durian's translation track, the core of the maximum significant wave height (Hs) was asymmetric with higher Hs and wider core in the right side than the left side. At a single position, the maximum Hs were always in the right-front quadrant of the typhoon center. Directional wave spectra at the forward and rightward points show the generation of low frequency wave of swell due to resonant effects. The wave spectra at the leftward and backward points have more complicated structures. The steady winter monsoon winds generate high waves. Monsoon winds weakly affect the Hs field near the typhoon's track and strongly away from the track, especially in the deep water area of the north SCS. Before the typhoon arrival, the monsoon- generated swell dominated; after the typhoon departure, the monsoon swell remained dominant (non-decaying) and the typhoon-introduced waves decayed gradually. These results reveal the unique features of SCS wave characteristics. 
(C) (P) This work is licensed under Creative

To Submit Your Article Click Here: $\quad$ Submit Article

DOI: 10.32474/MAOPS.2018.01.000116

Assets of Publishing with us
- Global archiving of articles

